\title{
Marketing Factors of Green Economic Effect on Consumers' Purchase Intention for the Market of Family-sedan in Taiwan
}

\author{
Shu-Hui Lan ${ }^{1}$, Tzu-Chun Sheng ${ }^{2} \&$ Kaiyue Zhang ${ }^{2}$ \\ ${ }^{1}$ Department of Marketing and Logistics Management, Ling Tung University, Taiwan, R.O.C. \\ 2 Department of Finance, Ling Tung University, Taiwan, R.O.C. \\ Correspondence: Tzu-Chun Sheng, Department of Finance, Ling Tung University, Taichung City, Taiwan, R.O.C. Tel: \\ 886-989-997-776. E-mail: morgan1125@teamail.ltu.edu.tw \\ Received: August 5, 2014 \\ doi:10.5430/rwe.v5n2p176 \\ Accepted: August 20, 2014 \\ Online Published: September 5, 2014 \\ URL: http://dx.doi.org/10.5430/rwe.v5n2p176
}

\begin{abstract}
The problems such as the global energy demand enhancing, greenhouse effect aggravating and climate externalizing and so on have worsen increasingly subsequent to the $21^{\text {st }}$ century. Enhancing consumers' awareness of environmental protection spurred the global automobile manufacturers to produce high-tech products and services with green features on the market. The automobile distributors take the concept of green marketing as the leading appeal to attract the consumers. Fuzzy Analytic Hierarchy Process is adopted in this study to analyze the best marketing strategy carried out while the automobile distributors are selling the products with the concept of green marketing and providing the services to consumers. The results show that the top 5 key green marketing factors influence the consumers on purchasing the family-sedans are "Cost on purchase, use and maintenance", "Ego green civil awareness of consumer", "Certification of green mark", "Low fuel consumption" and "Low emission". Comparatively speaking, the key factors are unable to influence the consumers on purchasing are "The practice of principle of equitable", "Deducting the consumption on production resources", "Advocacy of environment protection policy", "Recycling disposal of auto-body and components" and whether obtained "Subsidy". One excellent product is unable to achieve the perfect sales target if without appropriate marketing strategy. With the soar of global awareness of environment protection, the corporate all over the world combines the demands of environment protection with the marketing strategy mutually. As far as the automobile distributors are concerned, the marketing strategy has been the tendency without further delay drawn up by green marketing.
\end{abstract}

Keywords: family-sedan, fuzzy analytic hierarchy process, green consumption, green marketing, purchase intention

\section{Introduction}

A number of social values, including the rising awareness of environmental protection, the soar of consumerism and the widespread concern of underprivileged minority, have been transited since the late 1950s. The significance of fulfilling the consumers is set before the benefit in the concept of social marketing, the organization of corporate must consider initially the influences on its products and services to society. The problems such as the global energy demand enhancing, greenhouse effect aggravating and climate externalizing and so on have worsen increasingly subsequent to the $21^{\text {st }}$ century. The issues related to the environmental protection are regarded the economical development as equal imperative status by the governments and non-governmental organizations all over the world. Governments consecutively signed the international treaties related to the environmental protection and legislated for Green Acts in light of domestic demands. Simultaneously, developing green energy industry exploring new round of industrial revolution engulfed global industrial circles initially. The tendency of issues related to environmental protection has had an impact on consuming behavior from global consumers gradually since the consumers have linked up the awareness of environmental protection with practical purchasing behavior. Not only are the consumers willing to purchase the commodities with less hazardous, but pay more efforts on supporting environment protection (Kalafatis, Pollard, East, \& Tsogas, 1999; Jaime, 2007; Rex \& Baumann, 2007).

Global automobile industry has brought about the huge reformation since the consumers turned up their awareness of environmental protection increasingly. Traditionally, the automobile depredated the ecological environment, mainly resulted from the issues as the pollutions from the manufacturing factories, energy consuming, air pollution and disposal of waste vehicles. Enhancing consumers' awareness of environmental protection spurred the global automobile manufacturers to produce high-tech products and services with green features on the market. As the result, the concept of "Green Revolution" and "New Energy Era" has come about. Each segment of green concept such as 
the research and development of technology, product design, procurement of parts and components, production process, recycling and waste...etc is taken into consideration so that the automobile distributors take the concept of green marketing as the leading appeal to attract the consumers. Hence, the product of green marketing is able to combine with the concepts of eco-efficiency and consumers' value (Park \& Tshara, 2008).

The use and the origin of family-sedan in Taiwan have lasted over the half of century. Previous to the end of War World II, family-sedan had walked into Taiwanese society all the rage of modern. To sum up, two stages of Taiwan automobile industry development were divided subsequent to the War World II. The period of the first stage was from 1953 to 1984 when the foundation of light industry was developed little by little into the strength of heavy industry. Accordingly, Yulon Motor was founded as well as the first automotive manufacturer in 1953 in Taiwan under the policy protection carried out by Taiwan government. A couple of corporations were founded and introduced the foreign technology to enhance the production technology, proficiency and quality at once. A series of promotion programs of automotive industry development have been initially taken effect, reduced the costumes tariff considerably as well as diminished the protectionist policies by Taiwan government since 1985 as the second stage of Taiwan automotive industry development. Domestic contractors and overseas contractors have jointly designed and produced since Taiwan automotive industry development brought lined with international market. Meanwhile, policies were promoted and the automotive industry was aided to establish the complete collaborative mode of supply chain.

Automotive industry is mainly separated into two parts as the automotive manufacturing industry and the automotive component parts manufacturing industry. The automotive manufacturing industry refers to the industry which produces and assemblies a complete automobile; the automotive component parts manufacturing industry which manufactures the component parts is without assembly behavior. The sales market of Taiwan automobile has been influenced in that the international economical situation was instable and the domestic economic growth in Taiwan slowed sharply during recent years. The sales market of Taiwan automobile has been out of shadow of financial crisis of 2008 gradually, taking on the trend of growth for 3 years consecutively according to the statistics figures appeared by Taiwan Transportation Vehicle Manufactures Association and vehicle center (2013). The sales volume was approximately 370,000 units in 2012 , which declined slightly about $4 \%$ more than the previous year. Hence, the sales volume in Taiwan automobile industry was predicted to rise approximately $5 \%$ slightly by respective automotive corporations. Furthermore, the output value of Taiwan automobile components parts was NT $\$ 220$ billion roughly in 2012.

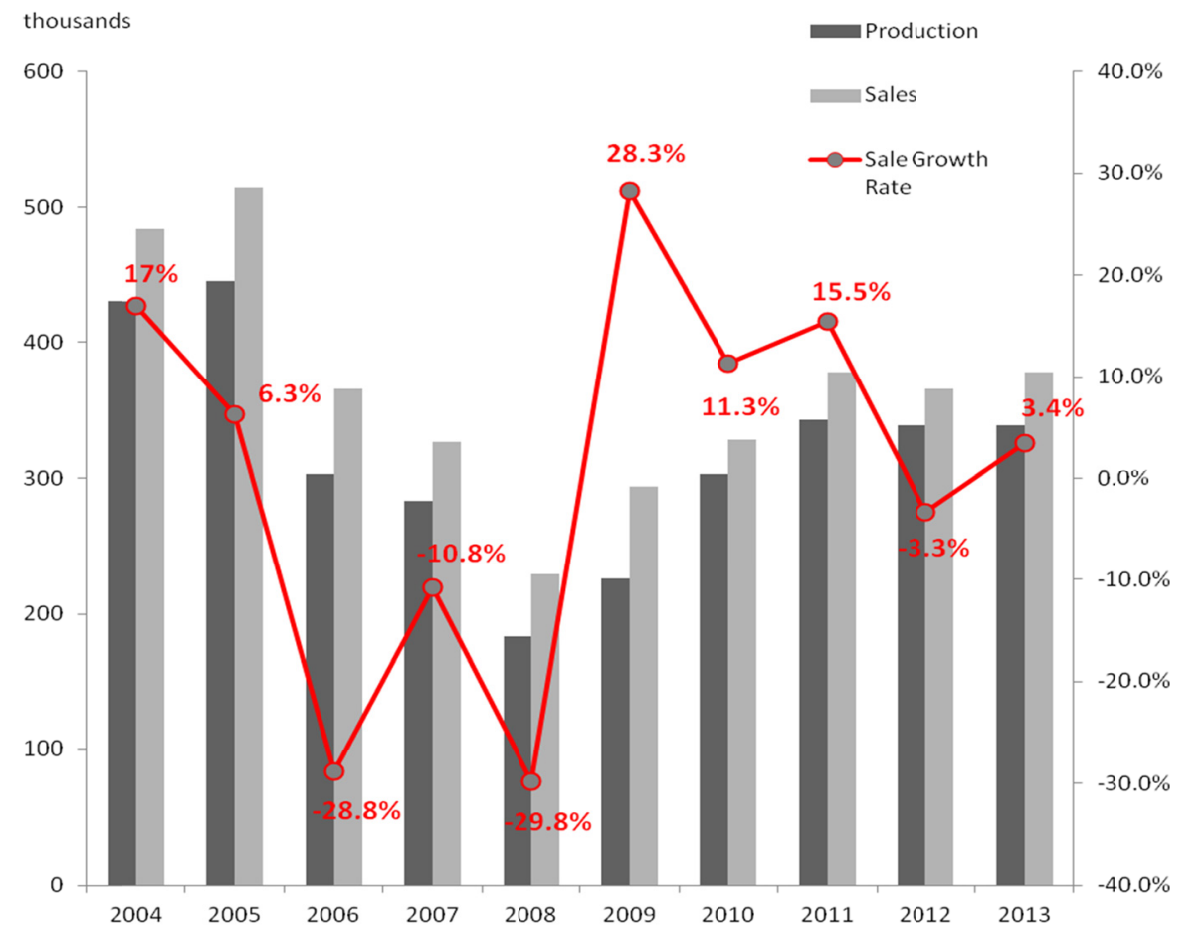

Figure 1. 2004-2013 production and sales volume in Taiwan automobile industry

Source: Taiwan Transportation Vehicle Manufacturers Association; Taiwan Automotive Research and Testing Center 
The product development of international automobile electronics major manufacturers has reflected the automobile manufacturers to the automobile design concept and consumers' preferences recently. The research and development of technology related to the energy saving depends on the hybrid power system, technology of new style diesel engine and research and development of battery set of electronics vehicles. As the result, the major automobile electronics manufacturers such as Bosch (Germany), Continental (Germany), SK (Germany), Aisin Siki (Japan), Denso (Japan), Johnson Control (the US), Magna (Canada), Hyundai (Korea) and so on have invested related researches and technological developments actively. For all global major automobile manufacturers plunged into the research and development of technology related to the green automobile in succession, governments as the major facilitators all over the world should undertake the responsibilities. Not only do the governments proclaim various policies of subsidy to aid the automobile manufacturers, but also offer the policies as the compensation promotions for the consumers and use-cost reduction to stimulate the demand on the market.

Green marketing has been one of the most frequent marketing strategies by automobile manufacturers for the time being. Energy saving and environmental protection related to the green issues have been the vital thinking while the automobile manufacturers are considering the transformation, taking the corporate responsibilities and establishing the marketing strategies. The concept of green marketing means the corporate cater to the habit in green consumption from the consumers, taking the green environmental protectionism as the value-oriented of products made by the corporate. The marketing events the corporate strived for meeting the consumers' needs of green products on the ground of the green culture as the production concept. The consumers' needs, corporate benefits and environmental protection benefits integrated into the marketing strategy are emphasized through the concept of green marketing. Green marketing fully takes the issues of resources utilization and environmental protection into account, which demands the corporate take the resources conservation exploitation and environmental protection benefits into consideration from the product design, the production and the use to the entire marketing process. Therefore, practicing the sustainable use of resources, protecting and improving the ecological environment are regarded as the ultimate goal. Nevertheless, how to draw up the marketing strategy to emerge determination as the corporate to the consumers? By which points of marketing means are focused to highlight the message of green concept? How to motivate the consumers with intense identity to stimulate the sales and brand image?

\section{Literature Review}

Green marketing has been the management model and the core of marketing strategy in the corporate over the years. Corporate events, production technology, product components and design have to take the ecology and environmental protection into account. Furthermore, green marketing is not only the tendency, but also the primary evaluated key point with strategic decision for the administrators in future investment, research and development and production and manufacturing in the $21^{\text {st }}$ century. The consumers combine the practical awareness of environmental protection with the concept of green purchase to carry out the strategic decision. The development of green marketing concept would be boycotted and impeded by green consumers providing that the green marketing concept were not taken account of by the corporate. Consequently, the offerings of product and service have initially reflected people's green demand (Winski, 1991; Karp, 1996; Ottman, 1998; Kalafatis et al., 1999). Therefore, green marketing has been orientated as the case study field by Journal of Marketing since 1971. For the adoption of green concept and environmental issues as the focus all circles, the numerous of studies regarding the "green marketing" and "green energy" has redoubled over the years explored by the academia. As the result, the studies regarding green marketing as the research topics has increased considerably since 2000 (Chamorro, Sergio, \& Francisco, 2009).

According to Peattie (1992), green marketing is the friendly policy to environment and the marketing event with strategy and tactics in the field of marketing. In addition, the concept of green consumption as the core of consumers' awareness is rising little by little. Environmental protection is regarded as one of decisive factors of purchase strategic decision by the population of $75 \%$ in developed countries. The corporate not only caters to and fulfills the needs of green consumption to publicize the green products, but also leads the concept of national green consumption. Consequently, green revolution is propelled by the consumers. Afterward the environmental awareness has been enhanced gradually by government legislators and consumers, so the corporate must take the potential and substantial environmental factors into account while making the administrative decision. The corporate initially integrated the environmental care into the marketing strategy, formed so-called "mandated corporate responsibility" (Varadarajan, 1992). Also, Varadarajan (1992) proposed the "Enviropreneurial Marketing" as the proper noun firstly, which emphasized the entrepreneurship is orientated in the ecology care and requisite of importance on the target of marketing strategy. Makower, Elkington and Hailes (1993) claimed that green consumption is supposed to avoid consuming excessive resources during the process in using, producing, wasting or severely influencing the products to the environment. Meanwhile, either the excessive packaging or the product with harmful material to people's 
health while consuming does not comply with the principle of green consumption. Drumwright (1994) examined the implication of marketing strategy to analyze the responsibilities during the purchase process in the number of corporate. Accordingly, the factors such as the corporate policies, the enthusiasm of entrepreneurship and the features of organizations will have an impact on the planning of marketing strategy in the corporate.

Some of the literature reviews are considered as the research topic to explore the policies regarding the government and encouraging the green consumption. Azzone and Bertele (1994) and Shi and Kane (1996) claimed the corporate invest the capital on the green business when the government interacted with the consumers to the environmental protection. Once the consumers arise their awareness of environmental protection, they will contribute a plenty of events regarding the concept of environmental protection to compel the government to focus on the issues of environmental protection and practical legislative action. According to Shi and Kane (1996) and Menon and Menon (1997) the interrelation between government and consumers will facilitate the corporate to undertake more responsibilities so as to avoid violating the law. Menon and Menon (1997) proposed the issues of environmental care has been remolded with the situation of global corporate intense competition. The establishment of corporate management strategy has been affected by increased environmental regulation system. The influence and demand on the campaign of environmental protection are manifested by the market value of environmental awareness. Therefore, corporate development policies and practical operation should take account of the set of marketing strategies as the confluence of social performance goals, corporate entrepreneurship orientations and the concept of an enviropreneurial of frame of marketing strategy integrated by the issues of environmental care. In other words, the issues of environmentalism have steadily linked up natural environment and social reformation with the social justice. Consequently, developing the paragon of corporate marketing strategy as the topic of environmental care enables the corporate to possess the competitive advantage.

The consumers supporting the concept of green consumption do not extensively exist in all consumption clusters, either. Ottman (1998) claimed the cognition on green consumption for consumers is difficult to relate with the demographic statistics. In other words, the manufacturers must deliver the information regarding green products to consumers more effectively than usual to strengthen the connection and communication with consumers, which increases the consumers' cognition and purchase probability. Straughan and Roberts (1999) found the age, gender and cognition to the consumers had a significant link in between. The object of green consumers is young with higher education, higher income, and higher social status. Generally speaking, female are the majority of the green consumers. Then, stakeholder of corporate is closely and inseparably related to the green marketing strategy carried out by corporate. Shrivastava (1994) declared the theory of organization emphasized the environment was formed by the economy, society, politics and technology. Taking the nature as the central environmental theory is rather vital while the crisis is occurring in natural environment. Jaime (2007) considered the corporate stakeholder promoted the influence on the environmental issues to the corporate management strategy. The corporate took account of the environmental issues and environmental factors to integrate into the marketing strategy. The stakeholder plays a significant role to the corporate investment plan, the frame of competitive strategy and the establishment of regulation.

Governments and non-government organizations all over the world initially developed a series of certified criteria of green product and green marks so as to enable the consumers to choose clearly the products which are beneficial for the environmental protection. Rex and Baumann (2007) took the green marks as the pertinent research field and extended from the consumers to the marketing strategy. Furthermore, Rex and Baumann (2007) set the criteria of 5 major structures as demand measurement, segmentation and target market, orientation and competitive advantage to the traditional marketing strategy to analyze the products with green marks, as well as try to provide the solution of low rate on market share for the products with green marks.

In brief, the outline of concept of green marketing is able to be described clearly by the literatures and studies above. The substance of green marketing the corporate took care of three sides such as the environment protection, responsibilities and the benefit of corporate stakeholder as the management idea. The corporate regarded the green culture as the core value so that the marketing concept, the way of marketing and marketing strategy are drawn up by the corporate, which is beneficial for the concept of green consumption to the consumers. As far as the automobile industry on this study topic is concerned, green marketing is able to extend further marketing strategy drawn up to create the core of green brands. The aim is to establish a chain of green marketing, including the product design, material purchase, product manufacture, logistics and distribution, product consumption and dynamic cycle procedure of recycling. 


\section{Methodology}

Analytic Hierarchy Process (AHP) was proposed by Thomas L. Saaty in 1971, one of the well-known Multiple Criteria Decision Making (MCDM) techniques, which is adapted to gather the opinions from the scholars and experts, systemizing and stratifying the complicated questions to deduct the risk of fault decision. The criteria per hierarchy take the ones above hierarchy as the benchmark to evaluate by the use of pairwise comparison method. The preference relation is supposed to meet the transitivity and accord with the consistency test while evaluating. The multiple criteria evaluation is made by the classical AHP, including the experts' opinions; yet fail to reflect the vague thoughts of human. Van Laarhoven and Pedrycz (1983), using the concept of fuzzy to solve the values in the pairwise comparison matrix with subjectivity, imprecision and vagueness...etc in traditional AHP, who stated Fuzzy Analytic Hierarchy Process (FAHP).

Literature review and Delphi technique were adopted to construct the hierarchical framework on this study. Following by the establishment of hierarchy architecture, each evaluator respectively enables to give pairwise comparison matrices of the ultimate goal and criteria by a nine-point scale. The level of Consistency of matrix is satisfying if the value of Consistency Ratio is less than 0.1 .

Buckley (1985) reported the adoption of geometric mean to integrate the opinions of experts enables to enhance consistency and precision of factor judgment. Subsequent to the combined opinions from all experts, the fuzzy positive reciprocal matrix is built immediately. Lambda-max method reported by Csutora and Buckley (2001) was applied on this study to calculate fuzzy weights. According to the fuzzy positive reciprocal matrix, there are several calculated procedures. First of all, to take the judgment matrix $T_{m}=\left[m_{i i^{\prime}}\right]$ with the grade of membership as 1 to seek crisp weight $W_{m}$, and to take the judgment matrices $T_{l}=\left[l_{i i^{\prime}}\right]$ and $T_{u}=\left[u_{i i^{\prime}}\right]$ with the grade of membership as 0 to seek the lower bound weights $W_{l}$ and upper bound weights $W_{u}$ respectively.

$$
\begin{gathered}
W_{m}=\left(W_{1 m}, W_{2 m}, \ldots, W_{i m}, \ldots, W_{n m}\right) \\
W_{l}=\left(W_{1 l}, W_{2 l}, \ldots, W_{i l}, \ldots, W_{n l}\right) \\
\mathrm{W}_{\mathrm{u}}=\left(\mathrm{W}_{1 \mathrm{u}}, \mathrm{W}_{2 \mathrm{u}}, \ldots, \mathrm{W}_{\mathrm{iu}}, \ldots, \mathrm{W}_{\mathrm{nu}}\right)
\end{gathered}
$$

Second, to take the crisp judgment matrix $T_{m}$ to proceed Consistency Test. Third, to seek adjustment coefficient to ensure the weight as fuzzy number.

$$
\begin{aligned}
Q_{l} & =\min _{1 \leq i \leq n}\left\{\frac{W_{i m}}{W_{\text {il }}}\right\} \\
Q_{u} & =\max _{1 \leq i \leq n}\left\{\frac{W_{i m}}{W_{\text {iu }}}\right\}
\end{aligned}
$$

Fourth, to seek adjustment lower bound weights $W_{l}^{*}$ and adjustment upper bound weights $W_{u}^{*}$.

$$
\begin{aligned}
& W_{l}^{*}=Q_{l} W_{l} \\
& W_{u}^{*}=Q_{u} W_{u}
\end{aligned}
$$

Fifth, to integrate $W_{l}^{*}, W_{m}$ and $W_{u}^{*}$, to obtain fuzzy weights $\widetilde{W}$.

$$
\widetilde{W}=\left(W_{l}^{*}, W_{m}, W_{u}^{*}\right)
$$

$\widetilde{T_{1}}=\left(l_{1}, m_{1}, u_{1}\right)$ and $\widetilde{T_{2}}=\left(l_{2}, m_{2}, u_{2}\right)$ are hypothesized as two triangular fuzzy numbers (TFNs). Chen (2000) reported the vertex method can be applied to define the distance between two TFNs.

$$
\mathrm{d}\left(\widetilde{T_{1}}, \widetilde{T_{2}}\right)=\sqrt{\frac{1}{3}\left[\left(l_{1}-l_{2}\right)^{2}+\left(m_{1}-m_{2}\right)^{2}+\left(u_{1}-u_{2}\right)^{2}\right]}
$$

The use of distance formula is able to make fuzzy number be defuzzier as $\mathrm{R}$.

$$
\mathrm{R}=\frac{d^{-}}{d^{-}+d^{*}}, \text { where } d^{-}=\mathrm{d}\left(\widetilde{T}, \widetilde{T}^{-}\right) \text {and } d^{*}=\mathrm{d}\left(\widetilde{T}, \widetilde{T}^{*}\right)
$$

The best case value is set up as $\widetilde{T}^{*}=(1,1,1)$, and the worst case value is as $\widetilde{T}^{-}=(0,0,0)$. The defuzzier is the subsequence of proceeding fuzzy number and produces the adequate index, the benchmark of comparison. On this study, the value of $\mathrm{R}$ stands for the value in the wake of defuzzier. The larger the value of $\mathrm{R}$, the more precedential sequence the factor stands for. 


\section{Hierarchical Structure of Problem in Application}

This study is in accordance with the literature review and Delphi technique to construct the hierarchical structure, as the Figure 2. The hierarchical structure comprises 5 criteria and 20 sub-criteria.

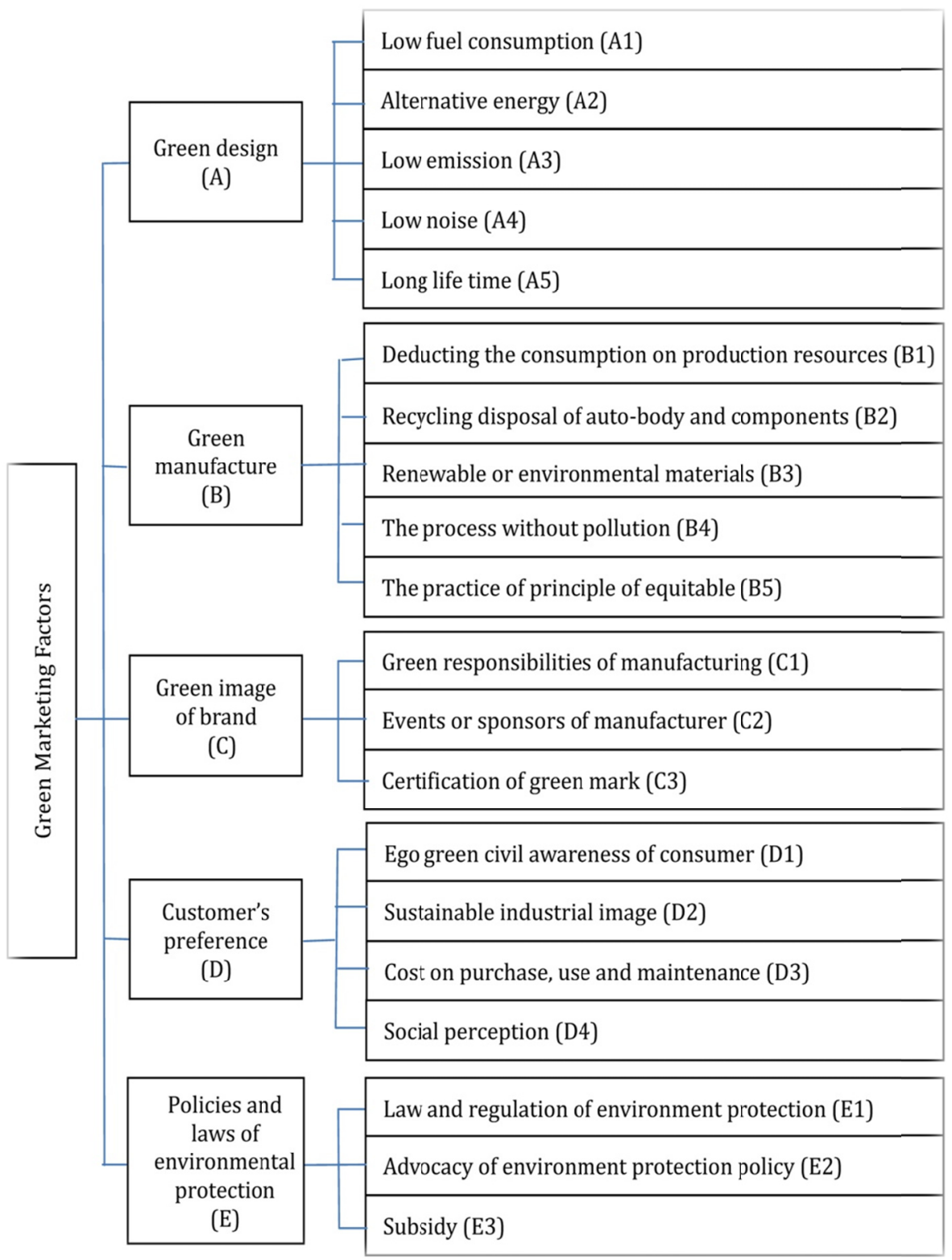

Figure 2. Hierarchical structure of problem in application

FAHP is adopted as the research method to analyze the best marketing strategy carried out while the automobile distributors are selling the products with the concept of green marketing and providing the services to consumers. The criteria of consideration are divided into the green design, the green manufacture, the green image of brand, customer's preference and policies and laws of environmental protection. The meaning and intention for all criteria are accounted for respectively as below:

- Green design (A): Green product is the strategic principle at the development stage. The design concept of green marketing is added into the process of product development, including the points considered in the procedure of green design. An excellent green design must take care of both enhancing design quality and reducing design cost.

- Green manufacture (B): While producing the green products, the manufactures adopt the production process with green manufacture except for the concept of green design considered at the development stage. The emission of improving the pollutants, deducting the waste of raw materials and lowering the energy consumption are taken care 
of the production process to manufacture the green products.

- Green image of brand (C): The concept of green marketing is regarded as the core factor of management and operation. The corporate attempts to build the green image of brand not unlike than it used to be. The corporate promotes the green products to lead more identification with the way of green market, which is driven by consumers. Therefore, the concept of national green consumption has arisen spontaneously.

- Customer's preference (D): Consumers' preferences to green marketing are mainly from consumers' self-conscious consumption habits. The consumers tried initially to buy green products with the least impact on environment after taking the concept of green market. The consumers carried out the purpose of consuming on one hand, on the other hand is to practice the promise by diminishing the damage to the environment through the consumption behavior of environment protection. So-called "green consumption" is the consumption by sustainability with more responsibility.

- Policies and laws of environmental protection (E): Government and consumers play the same role as the facilitator, while the corporate is regarding the concept of green marketing as the management core. The interrelationship between the government and consumers urge the corporate to do more responsibilities willingly for raising the business income, deducting the cost or sales tax and avoiding violating the law. Meanwhile, the concept of green marketing and promoted by government and the consumers' preference of green marketing encourage government to reply positively for legislation and promote all policies on environmental protection.

Several sub-criteria included below each criterion. The meaning and intention for all sub-criteria are accounted for respectively as below:

- Low fuel consumption (A1): The trend of high price of international crude oil and energy saving caused the consumers to purchase the automobile with low fuel consumption as the top priority. So as to enhance the high efficiency on engine and improve the economy of fuel, the major automobile manufacturers concentrated on development of various technologies with low fuel consumption.

- Alternative energy (A2): Alternative energy, the source of motive power, enables the vehicle to use the energy of gasoline and diesel oil. Hybrid electric vehicles, the technology of blended fuel, fuel cell and the technology of electric automobile as the alternative energies are used to drive the automobile.

- Low emission (A3): The automobile with green science and technology of new generation enables to reduce the greenhouse gas and the emission of pollutant damaging the environment. New criteria of environment protection are publicized by all nations able to reduce the emission of automobile, which is the norm as well.

- Low noise (A4): The technology of synergy drive, the technology of alternative energy and the design of sound insulation can reduce the noise effectively while starting the engine or the automobile is moving. The technology of reducing the noise eased the noise pollution from both inside and outside the car.

- Long life time (A5): The green technology of new generation extended the life time on automobile and components, which reduced the wastage of automobile and recycling cost as well as the chances of polluting.

- Deducting the consumption on production resources (B1): The automobile manufacturing are searching for the opportunities constantly to improve the process technology of current automobile assembly line as well as adopt the science and technology with various materials to the automobile design of new model. Nowadays, the complex materials with rapid development will greatly substitute for the traditional metals and plastic materials used for the auto-body and components. The production efficiency of the complete automobile has been advanced as well as the production resource has been economized by new science and technology.

- Recycling disposal of auto-body and components (B2): The materials for designing and manufacturing auto-body and components need to possess recycling feature. The volume of maintained components in the lifecycle, the vehicles have a far reaching effect on resource consumption of environment. A number of industrial countries promote to recycle the used components and parts of wasted vehicles in succession. Accordingly, the concept of "design for taking apart" and "design for recycling" has been the key point for automobile design and production.

- Renewable or environmental materials (B3): Renewable or environmental materials possess the features with easily discomposed and recycling, non-pollution and high-renewable. The designer adopted the concept of renewable or environmental materials at the initial phase of designing vehicles; for example, the use of auto-body coating without heavy mental and toxic compounds.

- The process without pollution (B4): The pollution is caused during the process of manufacturing the automobile. The adoption of new science and technology not only reduces the pollution under the automobile moving or 
polluted after waste disposed, but deducts the resource consumption and the add of waste while manufacturing the automobile. In addition, the quality and durability are enhanced; meanwhile, the needs the consumers for high quality products are met. Automobile manufacturers all over the world will introduce constantly new green science and technology to build production process with friendly-environment.

- The practice of principle of equitable (B5): The practice of principle of equitable refers to the producer and consumer are supposed to consider the respect to the human rights and nature while engaged in production and consuming something. Either the product or the service produced must not be acquired from the exploitation or discrimination. Similarly, the natural environment is supposed to be protected and respected fully.

- Green responsibilities of manufacturing (C1): The corporate regards the green concept as a responsibility to plan and implement the schemes actively regarding the environment protection and sustainable management. In order to carry out the green responsibilities, the corporate not only takes care of the management of its interior environment, but also be concerned about the management of suppliers simultaneously. Hence, the corporate needs to make an innovation, a change or a discard for fixed product design, raw material acquisition, equipment, process, and manpower allocation, which enables to fulfill the requirement of environmental energy saving.

- Events or sponsors of manufacturer (C2): Automobile manufactures responded while cooperating actively the policies of environmental protection of government and the events of environmental protection publicized by non-government. The manufactures announce their green marketing strategies to government while holding or sponsoring the events regarding the environmental protection. The consumers are able to understand the efforts to the environmental protection made by manufacturers through the events or the content of sponsor.

- Certification of green mark (C3): Green mark, awarding to the certification for qualification on various products of environment performance, is severely examined by all governments and non-governmental organizations. The manufacturers announced their determination of carrying out the green production and green marketing strategy while devoting their efforts to obtain the certification of green mark. Also, the consumers are able to identify whether the manufacturers have carried out the measurement of environment protection by green mark.

- Ego green civil awareness of consumer (D1): The consumers publicize the intension of green consumption on arising the green awareness and concept and self-expectations. For the adoption of enhancing ego green civil awareness by consumers, the corporate designs and produce green products willingly and carry out green marketing strategy. The effective interaction between supply and demand has been publicized the sustainable development to the entire society, economy and ecological environment.

- Sustainable industrial image (D2): The consumers with the concept of sustainable industrial image prefer to buy the products, from design to output, with the least impact on environment during the process. These consumers expect the corporate regards the sustainable development as the management goal as well as encourage the corporate to research and development, output and supply green products. Under the target of sales effects enhanced by the corporate, the sustainable development is also beneficial for the sustainable development of society and environment.

- Cost on purchase, use and maintenance (D3): The cost will influence the consumers' consumption intention when the consumers purchase, use and maintain the green products. In general, production cost is higher than the same type but traditional products while the green products are plunging into the market at preliminary stage. However, this is probable a phenomenon in the short term. The development of science and technology and impeccable production plan enable the cost on the purchase, use and maintenance to decrease gradually. With the enhancement of awareness of environment protection and the increase of income, the consumers will change their minds for green products with acceptable price.

- Social perception (D4): The consumers advance the intention of green consumption due to the external well social perception probably. The concept of new consumption fulfilled the basic consumption particularly, considering initially the added-value brought about by consumption in the meanwhile. Green marketing strategy is taken more easily by consumers as the concept of green consumption is a social fad.

- Law and regulation of environment protection (E1): Governments all over the world established the clear and practicable law and regulation of environment protection so as to protect natural environment, economize natural resources and build mechanism of social sustainable development. Law and regulation of environment protection regulated either directly or indirectly the rights and obligations between the consumers and manufactures. Law and regulation of environment protection enables the green marketing strategy to possess legitimacy of law and have influences on consumers. 
- Advocacy of environment protection policy (E2): Governments all over the world make the great efforts on the advocacy of environment protection policy. The extent of effort on advocacy of the environment protection policy government poured into will have an influence on consumers directly. The consumers are not only aware of the latest information and knowledge, but enable the manufacturers to understand the tendency of future development by advocacy of the environment protection policy.

- Subsidy (E3): The subsidy, incentives or allowance are offered to the consumers for green consumption by government. The production cost and selling price are probably arisen by green design of new generation, which reduce consumers' purchase intention. The aid from government will probably reduce the price on more traditional green products effectively.

\section{Empirical Results}

The sample object of the study is automobile distributors in Taiwan. The total 18 copies of expert questionnaires are given out, and the effective questionnaires are 16 copies, the effective ratio of which is $89 \%$. Each expert filled out the questionnaire by pairwise comparison method. Then, the expert questionnaires were complied by advance integration to proceed the analysis by self-written program as FAHP through Matlab.

According to the study method, fuzzy pairwise comparison matrix of each criterion in level 2 is complied as equation (11).

$$
T_{2}=\left[\begin{array}{ccccc}
(1,1,1) & (2.00,2.91,6.00) & (0.25,1.19,4.00) & (0.25,0.55,3.00) & (2.00,3.61,5.00) \\
(0.17,0.34,0.50) & (1,1,1) & (0.14,0.39,2.00) & (0.17,0.23,0.33) & (0.33,1.13,2.00) \\
(0.25,0.84,4.00) & (0.50,2.59,7.00) & (1,1,1) & (0.20,0.46,2.00) & (0.50,2.89,6.00) \\
(0.33,1.83,4.00) & (3.00,4.41,6.00) & (0.50,2.20,5.00) & (1,1,1) & (4.00,4.98,7.00) \\
(0.20,0.28,0.50) & (0.50,0.88,3.00) & (0.17,0.35,2.00) & (0.14,0.20,0.25) & (1,1,1)
\end{array}\right]
$$

The fuzzy judgment matrix as equation (11) is divided into three judgment matrixes as equation (12) to equation (14).

$$
\begin{gathered}
T_{2 l}=\left[\begin{array}{ccccc}
1 & 2.00 & 0.25 & 0.25 & 2.00 \\
0.17 & 1 & 0.14 & 0.17 & 0.33 \\
0.25 & 0.50 & 1 & 0.20 & 0.50 \\
0.33 & 3.00 & 0.50 & 1 & 4.00 \\
0.20 & 0.50 & 0.17 & 0.14 & 1
\end{array}\right] \\
T_{2 m}=\left[\begin{array}{ccccc}
1 & 2.91 & 1.19 & 0.55 & 3.61 \\
0.34 & 1 & 0.39 & 0.23 & 1.13 \\
0.84 & 2.59 & 1 & 0.46 & 2.89 \\
1.83 & 4.41 & 2.20 & 1 & 4.98 \\
0.28 & 0.88 & 0.35 & 0.20 & 1
\end{array}\right] \\
T_{2 u}=\left[\begin{array}{ccccc}
1 & 6.00 & 4.00 & 3.00 & 5.00 \\
T_{2 l} 0.50 & 1 & 2.00 & 0.33 & 2.00 \\
4.00 & 7.00 & 1 & 2.00 & 6.00 \\
4.00 & 6.00 & 5.00 & 1 & 7.00 \\
0.50 & 3.00 & 2.00 & 0.25 & 1
\end{array}\right]
\end{gathered}
$$

The priority vector weights of three matrixes as equation (12) to equation (14) are calculated as equation (15) to equation (17) respectively.

$$
\begin{aligned}
& W_{21}=\left[\begin{array}{lllll}
0.27 & 0.09 & 0.13 & 0.42 & 0.09
\end{array}\right] \\
& W_{2 m}=\left[\begin{array}{lllll}
0.24 & 0.08 & 0.20 & 0.40 & 0.07
\end{array}\right] \\
& W_{2 u}=\left[\begin{array}{lllll}
0.26 & 0.08 & 0.25 & 0.31 & 0.09
\end{array}\right]
\end{aligned}
$$

Making use of crisp judgment matrix as equation (13) proceeded Consistency Test to acquire $\lambda_{\max }=5.0101$ and $\mathrm{CI}=0.0025<0.1$. The adjustment coefficients are $Q_{2 l}=0.76$ and $Q_{2 u}=1.29$. The adjustment lower bound weights $\left(W_{2 l}^{*}\right)$ and the adjustment upper bound weights $\left(W_{2 u}^{*}\right)$ are obtained as equation (18) and equation (19) respectively.

$$
\begin{aligned}
W_{2 l}^{*} & =\left[\begin{array}{lllll}
0.20 & 0.07 & 0.10 & 0.32 & 0.07
\end{array}\right] \\
W_{2 u}^{*} & =\left[\begin{array}{lllll}
0.34 & 0.11 & 0.33 & 0.40 & 0.11
\end{array}\right]
\end{aligned}
$$

Accordingly, the fuzzy weights of each criterion in level 2 are showed as equation (20) to equation (24).

$$
W_{A}=\left[\begin{array}{lll}
0.20 & 0.24 & 0.34
\end{array}\right]
$$




$$
\begin{aligned}
& W_{B}=\left[\begin{array}{lll}
0.07 & 0.08 & 0.11
\end{array}\right] \\
& W_{C}=\left[\begin{array}{lll}
0.10 & 0.20 & 0.33
\end{array}\right] \\
& W_{D}=\left[\begin{array}{lll}
0.32 & 0.40 & 0.40
\end{array}\right] \\
& W_{E}=\left[\begin{array}{lll}
0.07 & 0.07 & 0.11
\end{array}\right]
\end{aligned}
$$

The fuzzy pairwise comparison matrices of sub-criteria under the criteria of the green design, the green manufacture, the green image of brand, customer's preference and policies and laws of environmental protection in level 2 are compiled respectively as equation (25) to equation (29).

$$
\begin{aligned}
& \begin{array}{r}
T_{31}=\left[\begin{array}{ccccc}
(1,1,1) & (2.00,4.40,7.00) & (0.50,1.86,3.00) & (3.00,4.60,7.00) & (0.33,2.65,5.00) \\
(0.14,0.23,0.50) & (1,1,1) & (0.20,0.31,0.50) & (0.25,1.09,3.00) & (0.17,0.55,2.00) \\
(0.33,0.54,2.00) & (2.00,3.27,5.00) & (1,1,1) & (2.00,3.39,6.00) & (0.25,1.76,5.00) \\
(0.14,0.22,0.33) & (0.33,0.92,4.00) & (0.17,0.30,0.50) & (1,1,1) & (0.20,0.52,2.00) \\
(0.20,0.38,3.00) & (0.50,1.82,6.00) & (0.20,0.57,4.00) & (0.50,1.91,5.00) & (1,1,1)
\end{array}\right] \\
T_{32}=\left[\begin{array}{ccccc}
(1,1,1) & (0.20,0.28,0.33) & (0.17,0.23,0.50) & (0.14,0.25,0.50) & (0.50,0.88,3.00) \\
(3.00,3.56,5.00) & (1,1,1) & (0.33,0.56,4.00) & (0.25,0.65,2.00) & (2.00,3.58,7.00) \\
(2.00,4.41,6.00) & (0.25,1.80,3.00) & (1,1,1) & (0.33,1.05,3.00) & (4.00,4.54,7.00) \\
(2.00,3.95,7.00) & (0.50,1.54,4.00) & (0.33,0.95,3.00) & (1,1,1) & (2.00,3.85,6.00) \\
(0.33,1.13,2.00) & (0.14,0.28,0.50) & (0.14,0.22,0.25) & (0.17,0.26,0.50) & (1,1,1)
\end{array}\right]
\end{array} \\
& T_{33}=\left[\begin{array}{ccc}
(1,1,1) & (0.25,2.46,5.00) & (0.17,0.70,3.00) \\
(0.20,0.41,4.00) & (1,1,1) & (0.17,0.52,5.00) \\
(0.33,1.44,6.00) & (0.20,1.93,6.00) & (1,1,1)
\end{array}\right] \\
& T_{34}=\left[\begin{array}{cccc}
(1,1,1) & (2.00,3.66,7.00) & (0.33,0.61,3.00) & (0.50,2.55,6.00) \\
(0.14,0.27,0.50) & (1,1,1) & (0.17,0.21,0.50) & (0.33,0.61,3.00) \\
(0.33,1.65,3.00) & (2.00,4.67,6.00) & (1,1,1) & (2.00,3.36,7.00) \\
(0.17,0.39,2.00) & (0.33,1.65,3.00) & (0.14,0.30,0.50) & (1,1,1)
\end{array}\right] \\
& T_{35}=\left[\begin{array}{ccc}
(1,1,1) & (2.00,3.41,7.00) & (0.33,1.34,7.00) \\
(0.14,0.29,0.50) & (1,1,1) & (0.17,0.35,3.00) \\
(0.14,0.75,3.00) & (0.33,2.89,6.00) & (1,1,1)
\end{array}\right]
\end{aligned}
$$

Accordingly, the fuzzy weights of sub-criteria under the criterion of the green design in level 2 are as equation (30) to equation (34).

$$
\begin{aligned}
& W_{A 1}=\left[\begin{array}{lll}
0.33 & 0.41 & 0.41
\end{array}\right] \\
& W_{A 2}=\left[\begin{array}{lll}
0.08 & 0.09 & 0.13
\end{array}\right] \\
& W_{A 3}=\left[\begin{array}{lll}
0.26 & 0.26 & 0.36
\end{array}\right] \\
& W_{A 4}=\left[\begin{array}{lll}
0.08 & 0.08 & 0.14
\end{array}\right] \\
& W_{A 5}=\left[\begin{array}{lll}
0.11 & 0.15 & 0.36
\end{array}\right]
\end{aligned}
$$

The fuzzy weights of sub-criteria under the criterion of the green manufacture in level 2 are as equation (35) to equation (39).

$$
\begin{aligned}
& W_{B 1}=\left[\begin{array}{lll}
0.07 & 0.07 & 0.08
\end{array}\right] \\
& W_{B 2}=\left[\begin{array}{lll}
0.22 & 0.22 & 0.36
\end{array}\right] \\
& W_{B 3}=\left[\begin{array}{lll}
0.24 & 0.34 & 0.37
\end{array}\right] \\
& W_{B 4}=\left[\begin{array}{lll}
0.21 & 0.30 & 0.41
\end{array}\right] \\
& W_{B 5}=\left[\begin{array}{lll}
0.06 & 0.07 & 0.07
\end{array}\right]
\end{aligned}
$$

The fuzzy weights of sub-criteria under the criterion of the green image of brand in level 2 are as equation (40) to equation (42).

$$
\begin{aligned}
& W_{C 1}=\left[\begin{array}{lll}
0.20 & 0.37 & 0.37
\end{array}\right] \\
& W_{C 2}=\left[\begin{array}{lll}
0.19 & 0.19 & 0.42
\end{array}\right] \\
& W_{C 3}=\left[\begin{array}{lll}
0.24 & 0.44 & 0.50
\end{array}\right]
\end{aligned}
$$

The fuzzy weights of sub-criteria under the criterion of customer's preference in level 2 are as equation (43) to 
equation (46).

$$
\begin{aligned}
& W_{D 1}=\left[\begin{array}{lll}
0.25 & 0.32 & 0.45
\end{array}\right] \\
& W_{D 2}=\left[\begin{array}{lll}
0.09 & 0.09 & 0.14
\end{array}\right] \\
& W_{D 3}=\left[\begin{array}{lll}
0.32 & 0.46 & 0.46
\end{array}\right] \\
& W_{D 4}=\left[\begin{array}{lll}
0.09 & 0.14 & 0.20
\end{array}\right]
\end{aligned}
$$

The fuzzy weights of sub-criteria under the criterion of policies and laws of environmental protection in level 2 are as equation (47) to equation (49).

$$
\begin{aligned}
& W_{E 1}=\left[\begin{array}{lll}
0.47 & 0.49 & 0.54
\end{array}\right] \\
& W_{E 2}=\left[\begin{array}{lll}
0.14 & 0.14 & 0.19
\end{array}\right] \\
& W_{E 3}=\left[\begin{array}{lll}
0.16 & 0.38 & 0.38
\end{array}\right]
\end{aligned}
$$

After that, the fuzzy weights of each criterion in level 2 multiplied by the fuzzy weights of each sub-criteria. The defuzzier values (R) of each sub-criteria and final fuzzy weights are presented in Table 1.

Table 1. Final fuzzy weights and defuzzier values

\begin{tabular}{clcc}
\hline Rank & \multicolumn{1}{c}{ Sub-Criteria } & Final Fuzzy Weights & $\begin{array}{c}\text { Defuzzier } \\
\text { (R) Values }\end{array}$ \\
\hline 1 & Cost on purchase, use and maintenance (D3) & $(0.102,0.184,0.184)$ & 0.1606 \\
2 & Ego green civil awareness of consumer (D1) & $(0.080,0.128,0.180)$ & 0.1347 \\
3 & Certification of green mark (C3) & $(0.024,0.088,0.165)$ & 0.1069 \\
4 & Low fuel consumption (A1) & $(0.066,0.098,0.139)$ & 0.1051 \\
5 & Low emission (A3) & $(0.052,0.062,0.122)$ & 0.0843 \\
6 & Green responsibilities of manufacturing (C1) & $(0.020,0.074,0.122)$ & 0.0822 \\
7 & Events or sponsors of manufacturer (C2) & $(0.019,0.038,0.139)$ & 0.0821 \\
8 & Long life time (A5) & $(0.022,0.036,0.122)$ & 0.0736 \\
9 & Social perception (D4) & $(0.029,0.056,0.080)$ & 0.0585 \\
10 & Law and regulation of environment protection (E1) & $(0.033,0.034,0.059)$ & 0.0438 \\
11 & Sustainable industrial image (D2) & $(0.029,0.036,0.056)$ & 0.0418 \\
12 & Low noise (A4) & $(0.016,0.019,0.048)$ & 0.0309 \\
13 & The process without pollution (B4) & $(0.017,0.024,0.045)$ & 0.0306 \\
14 & Renewable or environmental materials (B3) & $(0.016,0.022,0.041)$ & 0.0298 \\
15 & Alternative energy (A2) & $(0.011,0.027,0.042)$ & 0.0298 \\
16 & Subsidy (E3) & $(0.015,0.018,0.040)$ & 0.0292 \\
17 & Recycling disposal of auto-body and components (B2) & $(0.010,0.010,0.021)$ & 0.0265 \\
18 & Advocacy of environment protection policy (E2) & $(0.005,0.006,0.009)$ & 0.0145 \\
19 & Deducting the consumption on production resources (B1) & $(0.004,0.006,0.008)$ & 0.0067 \\
20 & The practice of principle of equitable (B5) & 0.0060 \\
\hline
\end{tabular}

It will be seen from the defuzzier values $(\mathrm{R})$ in Table 1 that the top 5 key green marketing factors influence the consumers on purchasing the family-sedans are "Cost on purchase, use and maintenance" $(\mathrm{R}=0.1606)$, "Ego green civil awareness of consumer" $(\mathrm{R}=0.1347)$, "Certification of green mark" $(\mathrm{R}=0.1069)$, "Low fuel consumption" $(\mathrm{R}=0.1051)$ and "Low emission" $(\mathrm{R}=0.0843)$. Comparatively speaking, the key factors are unable to influence the consumers on purchasing such as "The practice of principle of equitable" $(\mathrm{R}=0.0060)$, "Deducting the consumption on production resources" $(\mathrm{R}=0.0067)$, "Advocacy of environment protection policy" $(\mathrm{R}=0.0145)$, "Recycling disposal of auto-body and components" ( $\mathrm{R}=0.0265)$ and whether obtained "Subsidy" ( $\mathrm{R}=0.0292)$.

"Cost on purchase, use and maintenance" is the item the consumers accented the most among all the factors. It can be seen the consumers accented the expense of disbursement expected both at present and in the future. As far as the family sedan with the concept of related green energy and environment protection is concerned, the manufactures are supposed to analyze intensively its detailed cost-benefit. For example, the advantages are informed the consumers the higher price for this type of sedan, but extending its life time, deducting the fee of gas, the expense on national overall pollution remediation is deductable and the environmental quality is able to enhance...etc. Besides the preferential while buying the car, the manufacturers even emphasize on subsequence maintenance and discount programs to raise the consumers' consumption intention. "Ego green civil awareness of consumer" showed it is 
easier for the consumers who either have owned or possessed the awareness of environment protection accept the family sedan with the concept of related green energy and environment protection, which is the second vital factor. Hence, the manufacturers are able to educate or inspire consumers' ego green civil awareness to facilitate purchase intention through various advocacies and events. "Certification of green mark" is the third vital factor, which can be seen the consumers rely on the product certified by related organizations of government. The automobile distributors emphasize the certification of automotive examined by green mark of Environmental Protection Administration, Executive Yuan particularly, while selling the cars. "Low fuel consumption", the fourth vital factor, the proof of which can be acquired by the test value from Bureau of Energy, Ministry of Economic Affairs. Low fuel consumption stands for both environment protection and frugal to the consumers. The fifth vital element is "Low emission". With the numerous of vehicles increasingly, the waste gas general volume of emission of vehicle engine increased as well, which caused the global warming more and more seriously. For the sake to protect survival environment, people accent the situation of polluted emission increasingly. Therefore, the feature of low emission is able to be publicized intensively while the automobile marketing are sell the cars.

What is more, empirical results unveiled other messages worth to pay attention. First, "Subsidy" $(\mathrm{R}=0.0292)$ is not be quite accented by the consumers among 20 factors. The probable reason is people are unable to be inspired by limited subsidy government focus on. Next, the analysis result explored "Advocacy of environment protection policy" $(\mathrm{R}=0.0145)$ and "Deducting the consumption on production resources" $(\mathrm{R}=0.0067)$ have an ineffective influence on green marketing for automobile distributors. Finally, as far as "The practice of principle of equitable" $(\mathrm{R}=0.0060)$ is concerned, the least vital factor, which showed people engaged in buying cars should take the personal functions and features with more self-benefits into consideration. It cannot be taken into consideration whether the respect to the human being and the natural environment is taken into consideration by the consuming events while dealing with deeper issues.

\section{Conclusion}

As far as the most families are concerned, the purchase of automobile is one of the most major economical strategic decisions. In that the amount of money is much higher than the common purchases, the time and orientations of consideration to consumers takes even longer. The sales volume has decreased considerably comparing the volume a decade ago in Taiwan. Accordingly, automobile manufacturers rack their brains to manufacture more products meeting the consumers' needs. Coping with the soar of people's awareness of environment protection, the respective procedures such as the research and development, design, purchase, manufacturing, assembly, warehouse, marketing, maintenance and recycling greatly focus on the concept of environment protection. Nevertheless, how automobile distributors stimulate the consumption through the marketing strategy of green energy environment protection is an issue deeply concerned by the manufacturers. This study is explored to analyze the key factors of green marketing influenced by the purchase intention of automobile to the consumers through the expert questionnaire, Delphi Method and FAHP. It is expected that the relative weight and the rank of respective factors are able to be the references for green marketing strategies as automobile distributors draw up.

"Cost on purchase, use and maintenance" is emphasized to be one of the most beneficial publicized factors for the automobile distributors while the green marketing is progressing according to the research result. The manufacturers are supposed to grasp the pinch pennies from the consumers' psychology, and then analyze particularly the cost efficiency of recreation van with the concept of green energy environment protection. Besides, launching the promotion programs appropriately such as the various discount promotion, warranty extension, preferential interests of credit cards, extra free gifts or services on automobile purchase and maintenance enable to stimulate consumers' purchase intention. "Ego green civil awareness of consumer" which is the secondary vital factor appears the ego green civil awareness to Taiwanese enhanced gradually. As the result, the manufacturers should draw up the marketing strategy and train intensively the marketing personnel of front line with various marketing methods to discover either the people with ego green civil awareness or the prospects. "Certification of green mark" which has become one of the consideration indexes on automobile purchase due to the considerable brands and types of family-sedan is the third factor. Hence, automobile distributors are supposed to largely publicize the advantage for certified automobiles besides all automobile distributors should strive for the related certifications. "Low fuel consumption" and "Low emission" are the fourth and fifth factors separately. Energy conservation and carbon reduction has been a general action in that Taiwanese people who focus on living quality increasingly have tended to choose and purchase the vehicles with low fuel consumption and low emission. Moreover, both features are emphasized while the automobile distributors are marketing, which can adopt the analysis of cross-tabulation to the environment (i.e. either the highway or city drive way) and the consumers with different driving habits. By means of this, the consumers are able to be impressed deeply by both features.

In addition, the twentieth factor "Subsidy" is not as highly valued by the consumers, which is a notable point. The 
main reason is probable the disproportionate on government subsidy and the cost of automobile purchase from the consumers. Accordingly, the automobile distributors are able to inform the consumers regarding the subsidy programs from the government, but not the marketing points. Next, the analysis result revealed "Advocacy of environment protection policy" and "Deducting the consumption on production resources" influenced green marketing of automobile distributors ineffectively. Relatively speaking, "The practice of principle of equitable" is the least important factor, which demonstrated the consumers would not consider whether the human right and natural ecology are respected by the automobile manufacturing process or the entire consumption process while choosing and purchasing the automobiles. For this reason, the consumers obtained the shortage of information for a short while, whether the consumption practiced the principle of equality under the judgement.

One excellent product is unable to achieve the perfect sales target if without appropriate marketing strategy. With the soar of global awareness of environment protection, the corporate all over the world combines the demands of environment protection with the marketing strategy mutually. As far as the automobile distributors are concerned, the marketing strategy has been the tendency without further delay drawn up by green marketing.

\section{References}

Azzone, G., \& Bertele, U. (1994). Exploiting green strategies for competitive. Long Range Planning, 27(6), 69-81.

Buckley, J. J. (1985). Fuzzy hierarchical analysis. Fuzzy Sets and Systems, 17, 233-247. http://dx.doi.org/10.1016/0165-0114(85)90090-9

Chamorro, A., Sergio, R., \& Francisco, J. M. (2009). Characteristics of research on green marketing. Business Strategy and the Environment, 18, 223-229.

Chen, C. T. (2000). Extensions of TOPSIS for group decision-making under fuzzy environment. Fuzzy Sets and Systems, 144, 1-9. http://dx.doi.org/10.1016/S0165-0114(97)00377-1

Csutora, R., \& Buckley, J. J. (2001). Fuzzy hierarchical analysis: The Lambda-max method. Fuzzy Sets and Systems, 120, 181-195. http://dx.doi.org/10.1016/S0165-0114(99)00155-4

Drumwright, M. E. (1994). Socially responsible organizational buying: Environmental concern as a noneconomic buying criterion. Journal of Marketing, 58(3), 1-19.

Jaime, R. C. (2007). Re-evaluating green marketing strategy: A stakeholder perspective. European Journal of Marketing, 41(11/12), 1328-1358.

Kalafatis, P. S., Pollard, M., East, B., \& Tsogas, H. M. (1999). Green marketing and Ajzen's theory of planned behavior a cross-market examination. Journal of Consumer Marketing, 16(5), 441-460.

Karp, D. (1996). Values and their effect on pro-environmental behavior. Environment and Behavior, 28, 111-133.

Makower, J., Elkington, J., \& Hailes, J. (1993). The green consumer. USA: Viking Penguin Books.

Menon, A., \& Menon, A. (1997). Enviropreneurial marketing strategy: The emergence of corporate environmentalism as market strategy. Journal of Marketing, 61(1), 51-67.

Ottman, J. A. (1998). Green marketing: Opportunity for innovation. NTC Business Books.

Park, P. J., \& Tshara, K. (2008). Quantifying producer and consumer-based eco-efficiencies for the identification of key ecodesign issues. Journal of Cleaner Production, 16, 95-104.

Peattie, K. (1992). Green marketing. London: Pitman Publish.

Rex, E., \& Baumann, H. (2007). Beyond ecolabels what green marketing can learn from conventional marketing. Journal of Cleaner Production, 15, 567-576.

Shi, J., \& Kane, J. (1996). Green issues. Business Horizons, 39(1), 65-70.

Shrivastava, P. (1994). Castrated environment: Greening organization studies. Organization Studies, 15(5), 705.

Straughan, R. D., \& Roberts, J. A. (1999). Environmental segmentation alternatives: A look at green consumer behavior in the new millennium. Journal of Consumer Marketing, 16(6), 558 - 575.

Van Laarhoven, P. J. M., \& Pedrycz, W. (1983). A fuzzy extension of Saaty's priority theory. Fuzzy Sets and Systems, 11, 229-241. http://dx.doi.org/10.1016/S0165-0114(83)80082-7

Varadarajan, P. R. (1992). Marketing's contribution to strategy: The view from a different looking glass. Journal of the Academy of Marketing Science, 20(4), 323-343.

Winski, J. M. (1991). Big prizes, but no easy answers. Advertising Age. October 26, GR-3. 